\title{
A new megaspilid wasp from Eocene Baltic amber (Hymenoptera: Ceraphronoidea), with notes on two non- ceraphronoid families: Radiophronidae and Stigmaphronidae
}

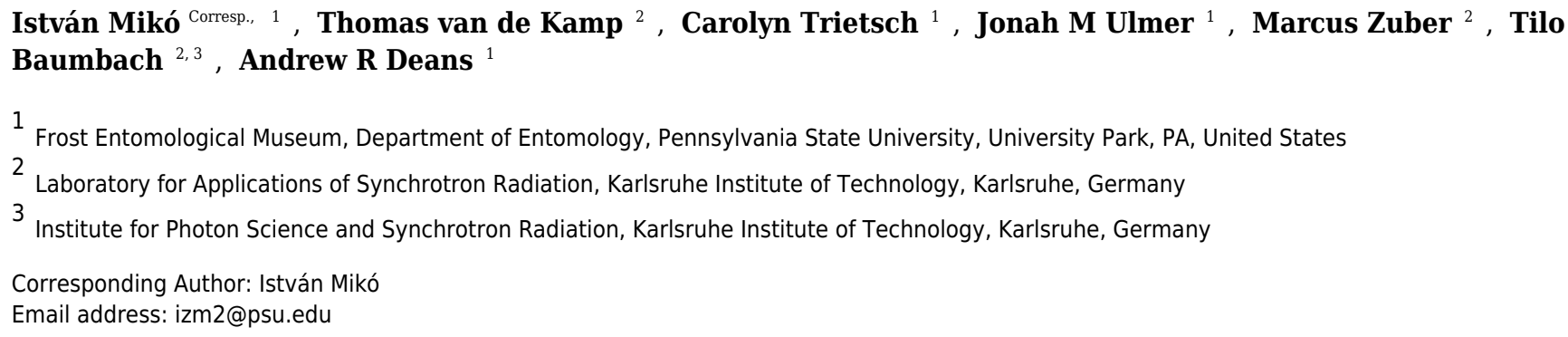

Ceraphronoids are some of the most commonly collected hymenopterans, yet they remain rare in the fossil record. Conostigmus talamasi Mikó and Trietsch, sp. nov. from Baltic amber represents an intermediate form between the type genus, Megaspilus, and one of the most species-rich megaspilid genera, Conostigmus. We describe the new species using 3D data collected with synchrotron-based micro-CT equipment. This non-invasive technique allows for quick data collection in unusually high resolution, revealing morphological traits that are otherwise obscured by the amber. In describing this new species, we revise the diagnostic characters for Ceraphronoidea and discuss possible reasons why minute wasps with a pterostigma are often misidentified as ceraphronoids. Based on the lack of ceraphronoid characteristics, we remove Dendrocerus dubitatus Brues 1937, Stigmaphronidae, and Radiophronidae from Ceraphronoidea and consider them as incertae sedis. We also provide some guidance for their future classification. 


\title{
A new megaspilid wasp from Eocene Baltic amber (Hymenoptera: Ceraphronoidea), with notes on two non-ceraphronoid families: Radiophronidae and Stigmaphronidae
}

6

István Mikó ${ }^{1}$, Thomas van de Kamp ${ }^{2}$, Carolyn Trietsch ${ }^{1}$, Jonah M. Ulmer ${ }^{1}$, Marcus Zuber ${ }^{2}$, Tilo Baumbach ${ }^{2,3}$, and Andrew R. Deans ${ }^{1}$

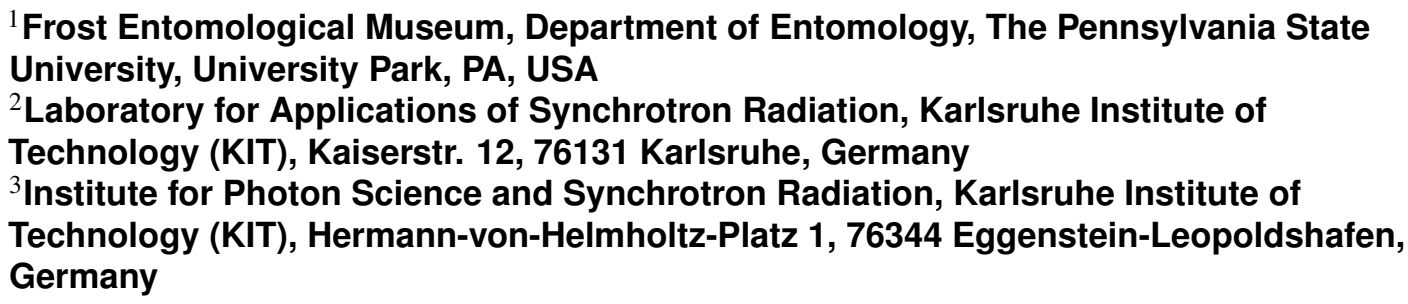

Email address: istvan.miko@gmail.com

\begin{abstract}
Ceraphronoids are some of the most commonly collected hymenopterans, yet they remain rare in the fossil record. Conostigmus talamasi Mikó and Trietsch, sp. nov. from Baltic amber represents an intermediate form between the type genus, Megaspilus, and one of the most species-rich megaspilid genera, Conostigmus. We describe the new species using 3D data collected with synchrotron-based micro-CT equipment. This non-invasive technique allows for quick data collection in unusually high resolution, revealing morphological traits that are otherwise obscured by the amber. In describing this new species, we revise the diagnostic characters for Ceraphronoidea and discuss possible reasons why minute wasps with a pterostigma are often misidentified as ceraphronoids. Based on the lack of ceraphronoid characteristics, we remove Dendrocerus dubitatus Brues 1937, Stigmaphronidae, and Radiophronidae from Ceraphronoidea and consider them as incertae sedis. We also provide some guidance for their future classification.
\end{abstract}

\section{INTRODUCTION}

Ceraphronoidea is a hymenopteran lineage with an enigmatic phylogenetic position and poorly understood natural history. Their minute body size and parasitoid lifestyle, along with a few antennal and fore wing characters, suggest a close relationship with Proctotrupomorpha (Ronquist et al., 1999; Engel and Grimaldi 2009). A myriad of other less-obvious morphological traits, however, including parts of the metasomal, genital and mesosomal skeletomuscular systems (Vilhelmsen et al., 2010; Mikó et al. 2013: Ernst et al. 2013), reveal many similarities to non-apocritan Hymenoptera. Even recent molecular phylogenetic studies have failed to place the superfamily with confidence, although they support that the superfamily, indeed, is not closely related to Proctotrupomorpha (Dowton et al., 1997, Heraty et al., 2011, Mao et al. 2015; Klopfstein et al., 2013, Peters et al., 2011, 2017; Branstetter et al., 2017). Irrespective of their phylogenetic position, recent ceraphronoids comprise a morphologically well-characterized group that can be readily separated from other hymenopterans based on the following traits. 
1. Compact mesosoma In Ceraphronoidea, the pronotum, mesopectus, metapectus, first abdominal tergum, and the metanotum comprise a single, compact sclerite (Fig. 1A). This modification is only found in some wingless hymenopterans, as the presence of the conjunctivae that allows mobility between the above-mentioned mesosomal regions is less important in flightless hymenopterans (Reid, 1941; Keller et al. 2014). The functional consequences of mesosomal compactness in ceraphronoids have never been explored. Most ceraphronoids are able to fly; therefore, mesosomal compactness most likely evolved for a different reason than that of flightless hymenopterans with a similarly compact mesosoma.

2. Orientation of the toruli and antennal bases The ventral position of the antennal insertion sites (toruli) is a well-known characteristic of Ceraphronoidea (Masner, 1993) and it is shared by some other apocritan taxa (e.g. Megalyroidea and Platygastroidea; Sharkey et al. (2012)). The orientations of the torular surface and the antennal base are, however, often overlooked traits of the superfamily. In Ceraphronoidea, the lateral torular margin is elevated relative to the median margin and therefore the antennal foramina, and the antennal scapes are oriented medially in a resting position (Figs 1 B, C).

3. Articulation between pronotum and mesoscutum In Ceraphronoidea, the pronotum and the mesoscutum have a unique, ball-and-socket type articulation that corresponds to sharp anterolateral edges on both the mesoscutum and pronotum (Fig. 11A) (Mikó and Deans, 2009). The notauli arise from these articulation (Figs. 2A, B) in Ceraphronoidea. While distinct anterolateral edges on the mesoscutum are present in Megalyridae, they never correspond with ball-and-socket articulations.

4. Wing venation All winged Ceraphronoidea have a stigmal vein that originates from the pterostigma or from the distal portion of the marginal vein posterior to the costal notch (Masner, 1993). Along with this, ceraphronoids have a single vein extending along the anterior margin of the fore wing. This vein is equipped with unique triangular elements (Figs $1 \mathrm{D}, \mathrm{E})$, whose functions and origins remain unknown. A single vein on the anterior wing margin is present in numerous other hymenopterans (e.g., aphidiine braconids) but the triangular elements are seemingly specific to Ceraphronoidea (IM, personal observation). In many Chrysidoidea the two wing veins on the anterior wing margin (costal and subcostal veins) are adjacent and may superficially look "fused", but they are always separated by a faint line (Olmi) 1994, Richards, 1939).

The two type specimens of the present paper are embedded in an approximately 33-55 millionyear-old (Gillung and Winterton, 2018; Larsson, 1978; Penney, 2010; Sadowski et al., 2017; Wolfe et al., 2016), somewhat cloudy piece of Baltic amber (Figs 3C, D 4 A-D). These specimens belong in Ceraphronoidea based on the the lyre-shaped notaulus and the orientation of the torulus and antenna (traits that are not obscured). As ceraphronoid experts, we examined the specimens with a light microscope at $230 \times$ magnification, and based on their general habitus (Gestalt) and the presence of a bifurcated anteromedian projection of the metanoto-propodeo-metapectal complex (Fig. $4 \mathrm{~A}$ ) we first classified them as Megaspilus, a genus that has never been recorded from any fossil deposit. However, after looking at the high resolution 3D data (see Supplementary 3D PDF of synchrotron-based micro-CT), we were able to observe otherwise-obscured traits and determine that the new species actually belongs in Conostigmus, as part of a species group that shares some key features with Megaspilus.

While small body size, reduced wing venation, and the presence of a pterostigma are often used to determine specimens as Ceraphronoidea, these characters occur in almost all hymenopteran superfamilies. Despite the above-listed clear and obvious ceraphronoid synapomorphies, it is common to find smaller Ichneumonoidea and Aculeata, especially Bethylidae and Dryinidae, misidentified as Ceraphronoidea in collections. Perhaps the most commonly misidentified are small specimens of the dryinid genus Aphelopus (Fig. 2C). One factor that may contribute to these misidentifications is the use of low-power microscopes for sorting and identification of specimens. Even the most distinct external traits specific to ceraphronoids are obscure with lower magnification and inadequate lighting. In such poor conditions, only those who have trained their eyes by looking at hundreds of ceraphronoid specimens are able to identify these taxa correctly. In some cases, the examination of fossil specimens is similar to studying specimens of recent taxa with a low quality microscope. Morphological traits are usually obscured by artifacts or debris, making them difficult to properly observe (if they can be seen at all).

The discovery of these Conostigmus specimens encouraged us to review fossil ceraphronoids and revise the classification of two hymenopteran families that are exclusively represented by fossils and currently classified in Ceraphronoidea. Radiophronidae and Stigmaphronidae are minute, winged wasps 

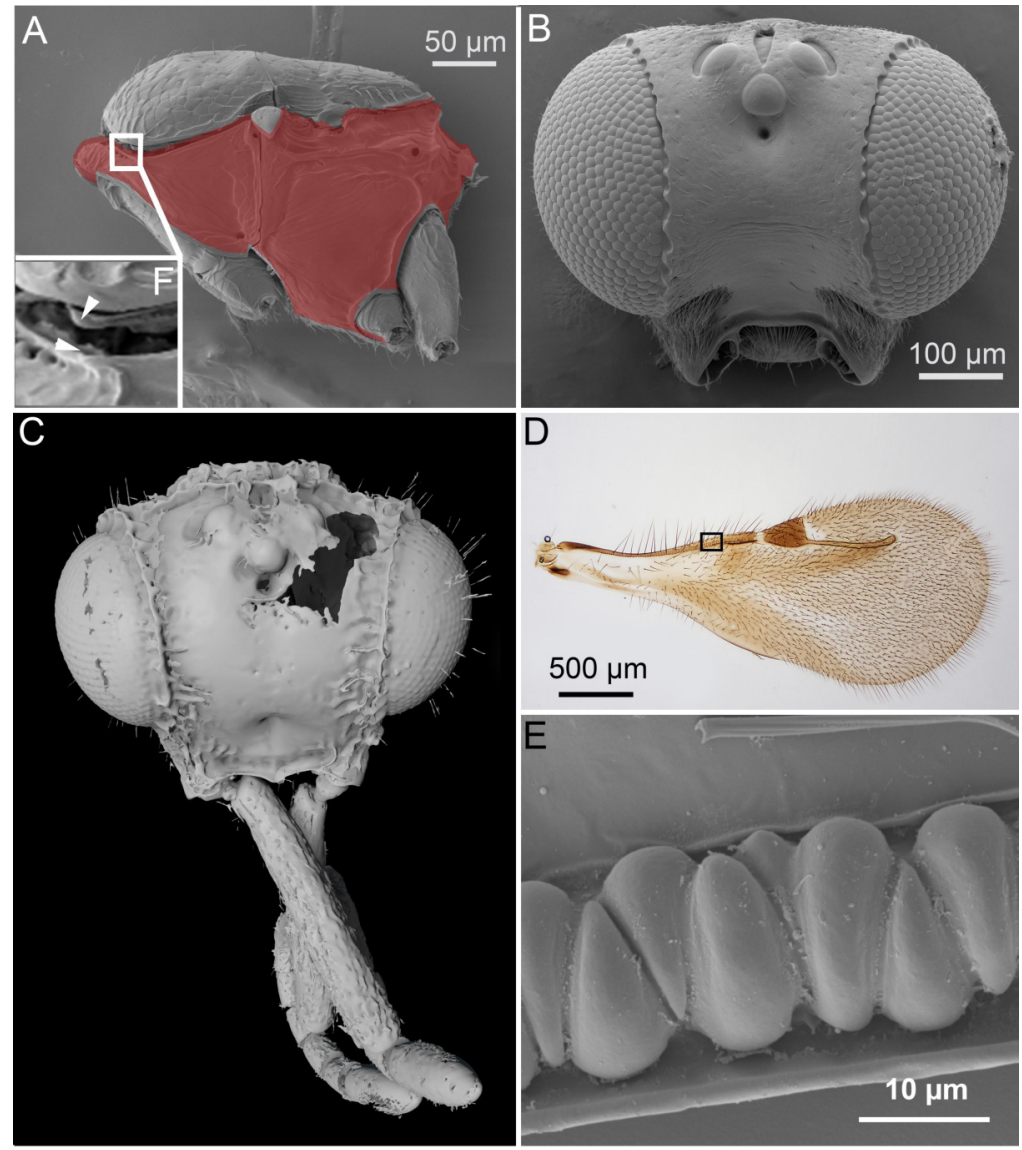

Figure 1. Unique ceraphronoid anatomical traits. (A) SEM micrograph of the mesosoma of Aphanogmus. The pronotum, mesopectus, metapectus, metanotum and first abdominal tergum, shown in red, comprise a single sclerite resulting in a compact mesosoma that can be found only in wingless Hymenoptera (e.g. Formicidae workers and Mutillidae females). The mesonotum and the pronotum have a unique ball-and-socket type articulation (smaller box (F) marked with arrowheads), a trait shared by Ceraphronoidea and Megalyroidea. The function of this articulation is unknown. (B) SEM micrograph of the head of Ceraphron (subgenus Eulagynodes) sp. showing the medially-oriented antennal sockets (toruli). (C) Surface-rendered 3D reconstruction of the head of Conostigmus talamasi Mikó and Trietsch nov. sp, bearing medially-oriented toruli and scapes. (D) Brightfield image of the fore wing of Masner lubomirus Deans and Mikó 2009 showing the typical ceraphronoid wing venation. There is a single vein along the anterior wing margin equipped with triangular elements and an unbroken stigmal vein that arises from the posterior third of the pterostigma (The region of Figure $\mathrm{E}$ is indicated by a small box). (E) SEM micrograph showing the triangular elements on the fore wing of Conostigmus sp. The function of these unique elements is unknown. 

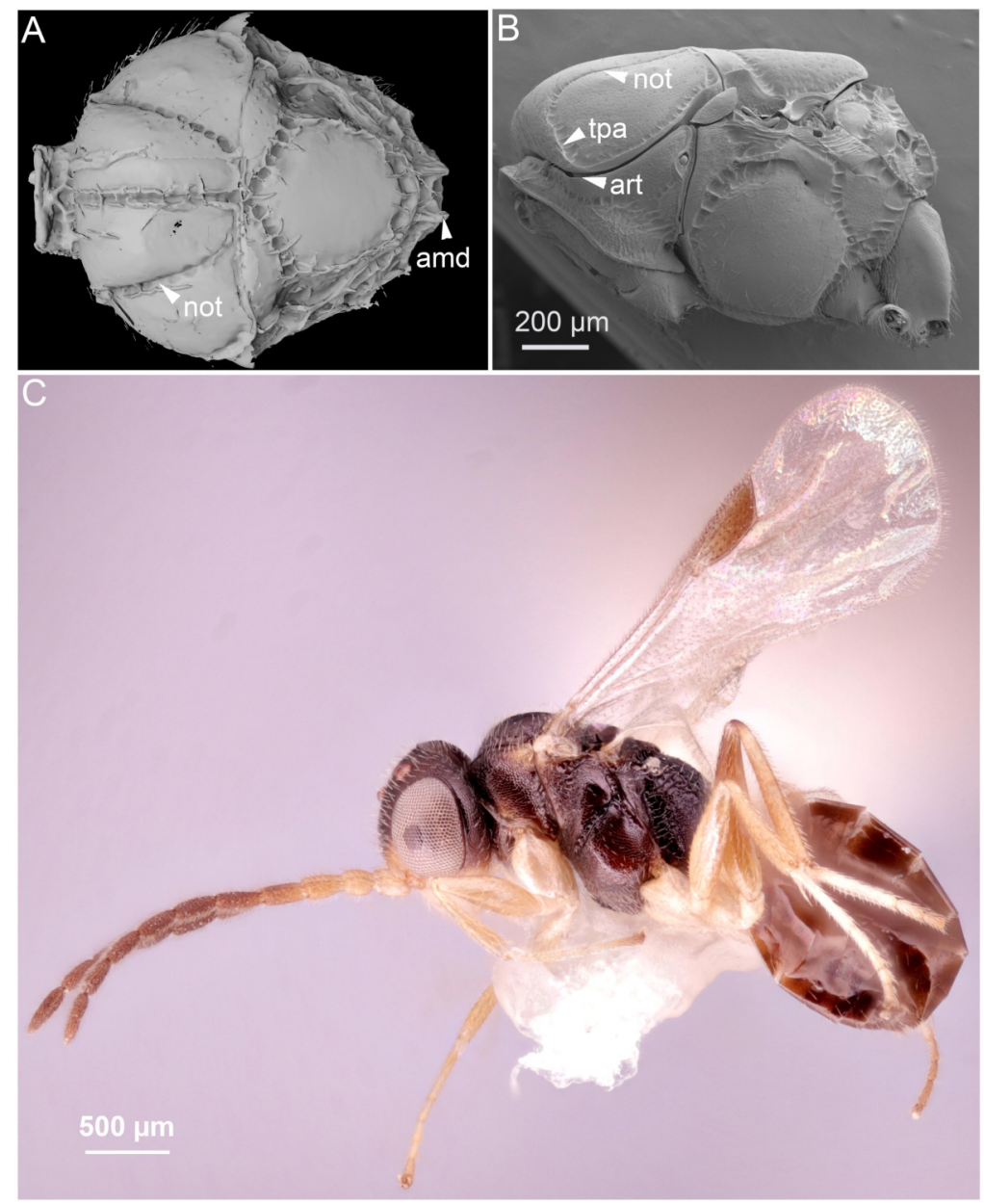

Figure 2. Comparison of ceraphronoid and chrysidoid morphology. (A) Surface rendered 3D reconstruction of the mesosoma of Conostigmus talamasi Mikó and Trietsch nov. sp. showing the lyre-shaped notauli (not) and the bifurcated anteromedian projection of the metapectal-propodeal complex (holotype, DEI-GISHym31819). (B) SEM micrograph of the mesosoma of Trichosteresis glabra (Boheman 1832). The anterolateral edge of the mesosoma corresponds to a ball-and-socket type articulation (art) between the mesonotum and the pronotum in Megalyroidea and Ceraphronoidea. The notaulus (not) is continuous with the anteromedian transverse sulcus (tpa) that arises from the pronoto-mesonotal articulation in Ceraphronoidea. (C) Brightfield image of the chrysidoid Aphelopus sp. These wasps, due to their minute body size, reduced wing venation, and large pterostigma, are often misidentified as Megaspilidae in collections (app=anteromedian projection). 

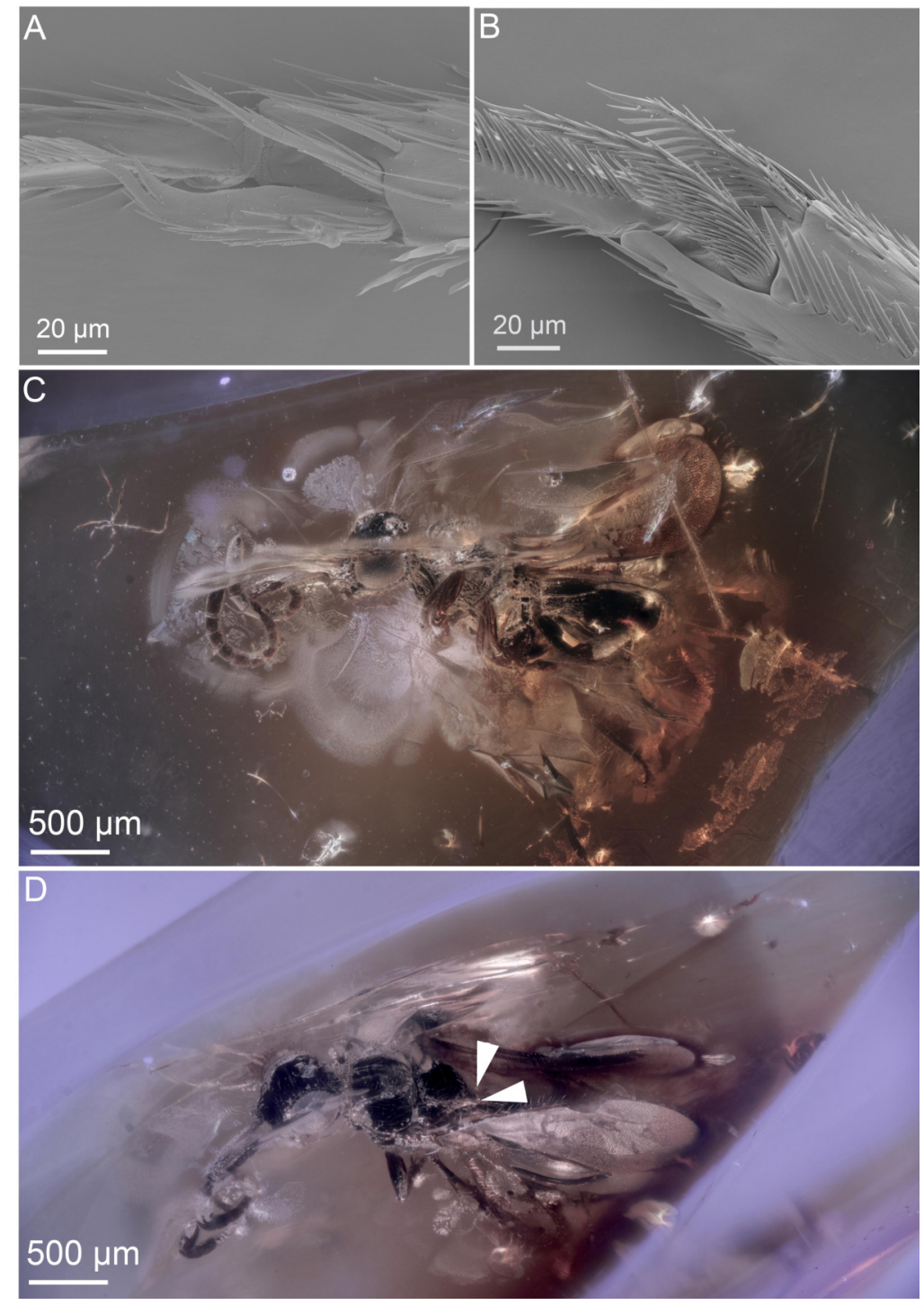

Figure 3. Ceraphronoid morphology in recent and fossilized specimens. (A) SEM micrograph showing the apical protibial spurs in Ceraphronidae. (B) SEM micrograph showing the apical protibial spurs in Megaspilidae. (C) Brightfield image showing the holotype of Conostigmus talamasi Mikó and Trietsch, lateral view (DEI-GISHym31819). (D) Brightfield image showing the holotype of Conostigmus talamasi Mikó and Trietsch, dorsolateral view, with arrows pointing to the bifurcate anteromedian projection of the metanoto-propodeo-metapectal complex (DEI-GISHym31819). 

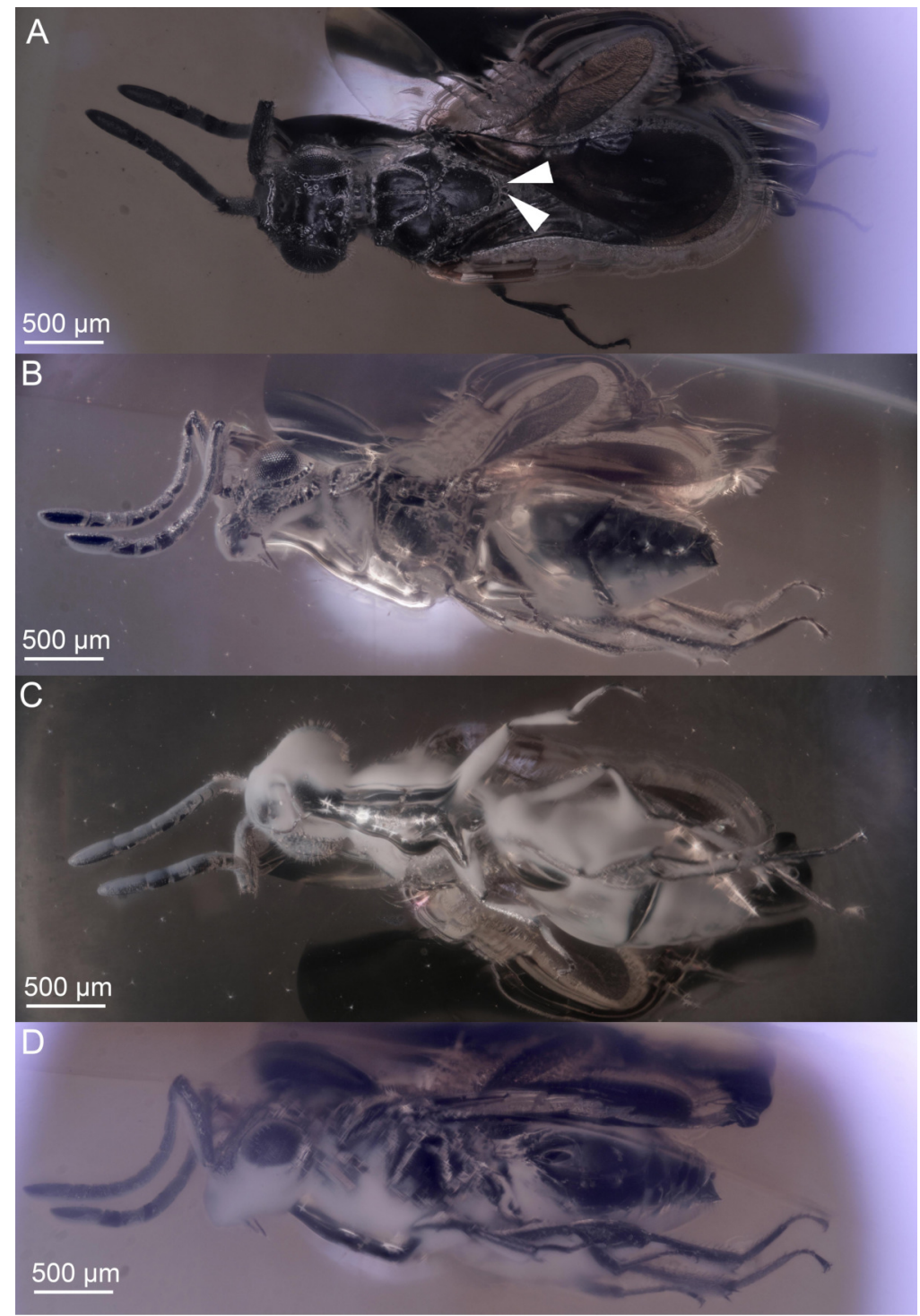

Figure 4. Brightfield images of the paratype (DEI-GISHym31820) of Conostigmus talamasi nov. sp. Mikó and Trietsch. A. Dorsal view, with an arrow pointing to the bifurcated anteromedian projection of the metanoto-propodeo-metapectal complex. B. Left lateral view. C. Ventral view. D. Right lateral view. 
that have a distinct pterostigma and, in some cases, two protibial spurs. Besides these traits, however, these two families do not share any other characteristics with Ceraphronoidea. Here, we remove them from the superfamily, leaving them incertae sedis, and provide some guidance for their future classification.

\section{MATERIALS AND METHODS}

The two specimens for the present study were obtained from the private collection of Baltic amber inclusions of Christel and Hans Werner Hoffeins (Hamburg, Germany) who bought them from commercial source at Amberif in Gdansk. Specimens are embedded in Polyester resin (Voss-Chemie, Uetersen) (Hoffeins, 2001) and are deposited in the Deutsches Entomologisches Institut (Müncheberg, Germany) with the accession numbers: DEI-GISHym31819 (holotype), DEI-GISHym31820 (paratype).

Morphological traits were observed and described using volume and surface rendered 3D models (Figures 1C, 2A, 5, Supplementary 3D PDF). Measurements of anatomical lines (Supplementary Table 1) were performed using the 3D measurement tool in Amira (version 5.6, FEI) using the ASTOR virtual analysis infrastructure at Karlsruhe Institute of Technology (KIT) (Mexner et al. 2017).

Synchrotron X-ray tomography was performed at the UFO imaging station of the KARA Synchrotron Radiation Facility at KIT. In order to achieve high image resolution despite the comparatively large size of the specimen, the latter was scanned in three steps. For each scan, 3,000 equiangularly-spaced radiographic projections were acquired in a range of $180^{\circ}$. The frame rate was set to 70 frames per second, resulting in a scan duration of about 43 seconds. A parallel polychromatic X-ray beam was spectrally filtered by $0.2 \mathrm{~mm} \mathrm{Al}$ to obtain a peak at about $15 \mathrm{keV}$. The detector consisted of a thin, plan-parallel lutetium aluminum garnet single crystal scintillator doped with cerium (LuAG:Ce), optically coupled via a Nikon Nikkor 85/1.4 photo-lens to a pco.dimax camera with a pixel matrix of $2008 \times 2008$ pixels. The magnification of the optical system was adjusted to $10 \times$, yielding an effective X-ray pixel size of $1.22 \mu \mathrm{m}$ (dos Santos Rolo et al. 2014). Tomographic reconstruction was performed with the GPU-accelerated filtered back projection algorithm implemented in the software framework UFO (Vogelgesang et al. 2012). The three tomographic volumes were registered and merged with Amira (version 5.6, FEI) using the ASTOR virtual analysis infrastructure at KIT (Mexner et al., 2017).

3D reconstruction followed the protocol described by Ruthensteiner and Heß (2008) and van de Kamp et al. (2014), using Amira for segmentation of every 20th slice of the tomographic volume. Automated interpolation between the labels was performed using the online image segmentation tool Biomedisa (https://biomedisa.de/) (Lösel and Heuveline, 2016). CINEMA 4D R18 (Maxon Computer GmbH) was employed for assembly of components, smoothing and polygon reduction. Subsequently, it was imported into Deep Exploration (version 6; Right Hemisphere), saved as Universal 3D file (U3D) and embedded into a PDF document with Adobe ${ }^{\circledR}$ Acrobat ${ }^{\circledR} 9$ Pro Extended.

Brightfield images of fossil specimens were taken with an Olympus BX43 compound microscope equipped with an Olympus DP73 digital camera. Image stacking was performed with Zerene Stacker (Version 1.04 Build T201404082055; Zerene Systems LLC, Richland, WA, USA). Extended focus images were annotated and modified with Adobe Photoshop 6 ${ }^{\mathrm{TM}}$ (Adobe Systems, San Jose, CA, USA) using the Adjust/Filter/Unsharp mask and Image/Adjustments/Exposure (Gamma correction) tools.

Taxonomic treatment including natural language (NL) phenotype representations were compiled in $\mathrm{mx}$ (http://purl.org/NET/mx-database). Terminology of the phenotype statements used in descriptions, are mapped to the Hymenoptera Anatomy Ontology (HAO, available at http:// ourl.obolibrary.org/obo/hao.owl), Phenotypic Quality Ontology (PATO, available at http: //purl.obolibrary.org/obo/pato.owl), Biospatial Ontology (BSPO, available at http: //purl.obolibrary.org/obo/bspo.owl) and Common Anatomy Reference Ontology (CARO, available at http: // obofoundry.org/). Wing venation terminology follows Mikó et al. (2014).

Natural language phenotype representations are in "Entity attribute: value" format. Semantic statements written in OWL Manchester syntax (http://www.w3.org/TR/owl2-manchester-syntax/) were generated in Protégé 5.0.0-beta-16 (http: //protege.stanford.edu/) following Balhoff et al. (2013); Mikó et al. (2014). The OWL (http: //www.w3.org/TR/owl2-overview/; accessed February 4, 2014) representation of the full data set is stored as a single Resource Description Framework (RDF)-XML file (http://www.w3.org/TR/REC-rdf-syntax/; accessed 12 March 2017) in the Github repository (https://github.com/hymao/hymao-data).

The electronic version of this article in Portable Document Format (PDF) will represent a published work according to the International Commission on Zoological Nomenclature (ICZN), and hence the 
new names contained in the electronic version are effectively published under that Code from the electronic edition alone. This published work and the nomenclatural acts it contains have been registered in ZooBank, the online registration system for the ICZN. The ZooBank LSIDs (Life Science Identifiers) can be resolved and the associated information viewed through any standard web browser by appending the LSID to the prefix http://zoobank . org//. The LSID for this publication is: [ LSID urn:lsid:zoobank.org:pub:0B233959-77FE-46F1-AB82-15C7F816D0BA].

The online version of this work is archived and available from the following digital repositories: PeerJ, PubMed Central and CLOCKSS.

\section{RESULTS}

\section{Conostigmus}

The new species belongs in Conostigmus based on the presence of a distinct sternaulus (ste: Fig. 5A), a shorter posterior ocellar line (POL) than ocular-ocellar line $(\mathrm{OOL})(\mathrm{Figs} \sqrt{1} \mathrm{C}, 5 \mathrm{~B}, \mathrm{C})$ and the presence of a preoccipital carina (Figs $1 \mathrm{C}$, $, 5 \mathrm{~A}, \mathrm{~B}, \mathrm{C}$ ). These traits are absent from Dendrocerus, Trichosteresis, and Platyceraphron; clavate female antenna and F1 length (proximodistal anatomical line) shorter than the combined length of F2 and F3 are traits that are present in Conostigmus and absent from Megaspilus.

\section{Conostigmus talamasi Mikó and Trietsch sp. nov.}

urn:lsid:zoobank.org:act:B9777D1A-78D0-48B2-90F7-511DE4830EA9

Figures $1 \mathrm{C}, 3 \mathrm{~B}, \mathrm{C}, 4,5$

Diagnosis The new species differs from other Conostigmus species in the presence of a bifurcated anteromedian projection of the metanoto-propodeo-metapecto-mesopectal complex (app: Fig. 5C). The anteromedian carina of the syntergite (acs: Fig. $5 \mathrm{C}$ ) is inserted into the concavity between the projections. The anteromedian projection of the metanoto-propodeo-metapecto-mesopectal complex in Conostigmus talamasi is distinct, but shorter than that of Megaspilus species.

\section{Description (Supplementary Table 1)}

Body length universal: $2007.29 \mu \mathrm{m}, 2411.09 \mu \mathrm{m}$.

Head: Head width vs. head height: $\mathrm{HW}: \mathrm{HH}=1.183$, 1.192. Head width vs. interorbital space (HW/IOS) Female: 1.861, 2.011. Dorsal carina of occipital depression count: present. Dorsal carina of occipital depression medial continuity: discontinuous medially. Occipital carina sculpture: crenulate. Median flange of occipital carina count: absent. Submedial flange of occipital carina count: absent. Dorsal margin of occipital carina vs. dorsal margin of lateral ocellus in lateral view: occipital carina is ventral to lateral ocellus in lateral view. Preoccipital lunula count: present. Preoccipital ridge count: present. Preoccipital furrow count: present. Preoccipital furrow anterior extension: adjacent anteriorly to the posterior margin of the median ocellus. Preoccipital furrow anterior region vs posterior region sculpture: posterior region crenulate, anterior region smooth or finely reticulate. Preoccipital furrow anterior region width vs posterior region width: as wide anteriorly as posteriorly. Preoccipital carina count: present. Preoccipital carina shape: interrupted dorsally and represented by irregular, not continuous carinae. Preoccipital carina and occipital carina structure: occipital carina complete, preoccipital carina fused laterally with preorbital carina. Female OOL: POL: LOL: 1.1:1.2:1,1.2:1.7:1. Postocellar carina count: absent. Preocellar pit count: present. Randomly sized areolae around setal pits on upper face count: absent. Antennal scrobe count: absent. Transverse striation on upper face count: present. Transverse scutes on upper face count: absent. Transverse frontal carina count: absent. Frontal ledge count: absent. Rugose region on upper face count: present. Anterior ocellar fovea shape: fovea not extended ventrally into facial sulcus. Facial pit count: facial pit present. White, thick setae on upper face count: absent. Ventromedian setiferous patch and ventrolateral setiferous patch count: absent. Supraclypeal depression count: absent. Intertorular carina count: present. Median process on intertorular carina count: present, extending from intertorular carina towards dorsal margin of clypeus. Median process of intertorular carina structure: process extends across intertorulal area to dorsal margin of clypeus. Intertorular ridge vs. epistomal ridge: fused medially. Intertorular area count: present. Median region of intertorular area shape: convex. Torulus position relative to anterior ocellus and distal margin of clypeus: torulus not reaching epistomal sulcus, closer to distal margin of clypeus than anterior ocellus. Torulo-clypeal carina count: absent. Subtorular carina count: absent. Subantennal groove count: absent. Posterolateral process of gena count: absent. Ocular impression and post ocular orbital carina count: present. Ocular impression 


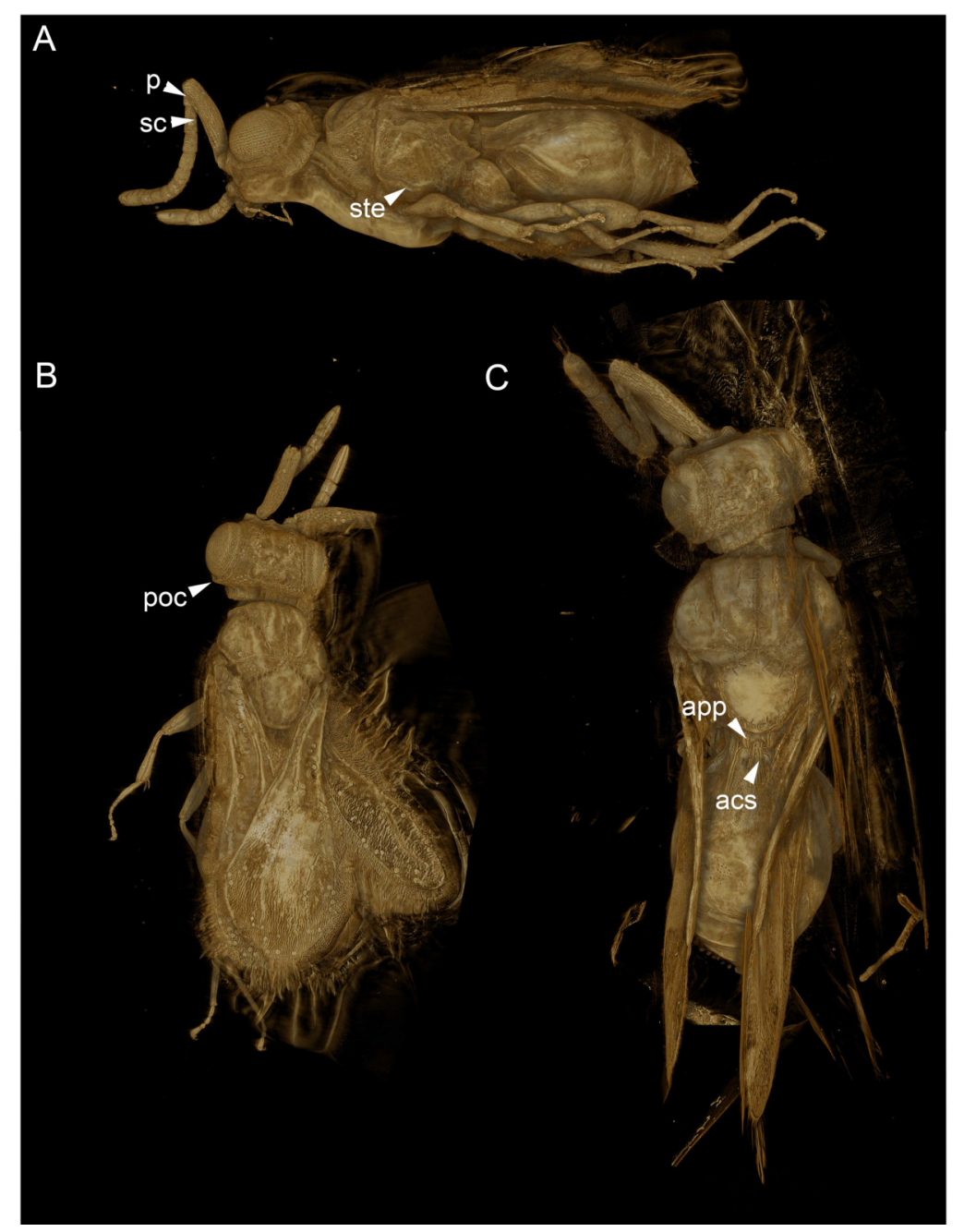

Figure 5. Volume rendered 3D micrographs showing Conostigmus talamasi sp. nov. Mikó and Trietsch. A. Paratype, lateral view. B. Paratype, dorsal view. C. Holotype, dorsal view. Abbreviations: acs=anteromedian carina of the syntergite, app=anteromedian projection of the metanoto-propodeo-metapecto-mesopectal complex, $\mathrm{p}=$ pedicel, poc=preoccipital carina, $\mathrm{sc}=\mathrm{scape}$, ste $=$ sternaulus

(DEI-GISHym31820). 
sculpture: scalloped (foveae composing ocellar impression adjacent, sometimes not separated from each other). Mandibular tooth count: 2. Mandibular lancea count: absent. Maxillary palpomeres count: 5-6.

Antennae: Flagellar scrobe of the scape count: present. F1 length vs F2+F3 length: F1 shorter than F2+F3. F1 length / F2 length: 1.59, 1.55. F6 length / F7 length+F8 length: 0.59, 0.47. Scape length / F1 length+F2 length: 2.1, 2.25. Scape length / F2 length: 5.4, 5.74. Female scape length vs. pedicel length: 3.8,4.2. Female F1 length vs. pedicel length: F1 as long as pedicel (1.0-1.1). Female ninth flagellomere length: F9 longer than F7+8.

Mesosoma: Foveolate sculpture on body count: absent. Mesosoma shape: not compressed laterally, as wide as high or wider than high. Pronope count: present. Transverse pronotal sulcus (anterodorsal branch of pronotal y) count: present. Epomial carina count:absent. Posterodorsal branch of pronotal Y count: present. Ventrolateral invagination of the pronotum count: present. Annullar pronotum count: present. Ventromedian region of pronotum and anteroventral region of mesopectus continuity: pronotum and mesopectus continuous ventromedially. Lateroventral invagination of the propleuron count: absent. Mesonotal fossa of the pronotum and pronotal condyle of the mesonotum count: present. Mesonotum anterolateral margin shape: square. Median mesoscutal sulcus count: present. Median mesoscutal sulcus posterior end location: adjacent to transscutal articulation. Scutoscutellar sulcus vs. transscutal articulation location: adjacent. Notaulus count: present. Notaulus posterior end location: adjacent to transscutal articulation. Posterior end of notaulus vs. posterior end of antero-admedian line location: notaulus extends more posteriorly than antero-admedian line. Transscutal articulation completeness: complete. Lateral carina on the mesoscutellum count: absent. Axillular carina count: present. Axillular carina shape: left and right carina continuous posteromedially forming a U-shape carina on the mesoscutellar axillar complex. Axillular setae count: absent. Posterolateral margin of mesoscutellum shape: blunt. Posteromedian process of the mesoscutellum count: absent. Anteromedian projection of the metanotopropodeo-metapecto-mesopectal complex count: present. Anteromedian projection of the metathoraxpropodeum complex shape: bilobed. Anteromedian projection of the metathorax-propodeum complex curvature lateral in view: straight. Sternaulus count: present. Sternaulus length: elongate, exceeding $3 / 4$ of mesopleuron length at level of sternaulus. Longitudinal striae extending from crenulae of anterior mesopleural sulcus to mesopleural pit count: absent. Speculum ventral limit: not extending ventrally of pleural pit line. Mesometapleural sulcus count: present. Ventral invagination of mesometapleural sulcus presence: absent. Epicnemial carina count: complete. Epicnemial pit count: absent. Epicnemium posterior margin shape: anterior discrimenal pit present; epicnemial carina curved. Mesodiscrimen count: present. Anterior metapleural carina count: absent. Metapleural carina count: present. Metapleural carina vs. propodeal spiracle: metapleural carina extending ventrally of propodeal spiracle. Ventral projection of the metapleural carina count: present. Ventral invagination of the metapleural carina count: absent. Propodeal spiracle dilator muscle apodeme pit location: On metapleural carina. Lateral propodeal carina count: present. Lateral propodeal carina shape: inverted "U" (left and right lateral propodeal carina are adjacent to the antecostal sulcus of the first abdominal tergum submedially). Median propodeal carina count: absent. Posterior propodeal projection count: present. Posterior propodeal projection shape: simple. Propodeal and metacoxal verricules count: absent. Posterodorsal metapleural area shape: trapezoid. Posterior line of the posterodorsal metapectal area count: present. Transverse line of the metanotum-propodeum vs. antecostal sulcus of the first abdominal tergum: adjacent sublaterally. Carina limiting posteriorly antecosta count: present. Metapecto-propodeal conjunctiva count: present. Posterior margin of nucha in dorsal view shape: straight.

Wings: Stigmal vein of fore wing count: present. Pterostigma of fore wing count: present. Hind wing reduction: well developed.

Legs: Calcar shape: bifid. Mesotibial spur count: 2 . Mesobasicoxa width vs. metabasicoxa width: metabasicoxa distinctly wider than mesobasicoxa. Posterior mesosomal comb count: absent.

Metasoma: S1 length vs. shortest width: S1 wider than long. Transverse carina of petiole count: present. Transverse carina on petiole shape: straight. Basal, longitudinal carinae on syntergum count: more than 5. Transverse sulcus of first metasomal sternum count (S1 count): present. Waterston's evaporatorium count: absent.

\section{Locality of type specimens}

Gulf of Gdańsk (Baltic amber) 


\section{Etymology}

The new species is named after Elijah Talamas (Florida State Collection of Arthropods), who drew our attention to these unique fossils.

\section{DISCUSSION}

\section{Megaspilus vs. Conostigmus}

Based on the latest phylogenetic analysis (Mikó et al., 2013), and preliminary phylogenomic data from an ongoing molecular study using ultra-conserved elements (UCEs) (Bonnie Blaimer, pers. comm.) Conostigmus is polyphyletic and includes Megaspilus. Until Dessart's revisions (1972, 1981) of Nearctic and Palaearctic species, Megaspilus was a broad taxonomic concept that essentially included all larger megaspiline species with an acute ocellar triangle (Conostigmus-type, in contrast to a Dendrocerus-type obtuse ocellar triangle), well-defined sternaulus, distinct posterior orbital carina and/or some rugulose sculpture on the frons. Dessart (1972) narrowed the generic concept of Megaspilus to include only those species that have an acute ocellar triangle, sternaulus, bifurcated anteromedian projection, and elongate female first flagellomere. The ocellar triangule shape and presence of the sternaulus are shared with numerous Conostigmus species, leaving the bifurcated anteromedian projection and the elongate female proximal flagellomeres as diagnostic features for Megaspilus.

The bifurcated anteromedian projection of Megaspilus is clearly derived from the elevated and medially-projected lateral propodeal carinae. This bifurcated condition can be found in certain Ceraphron and Dendrocerus (Alekseev, 1978) species, and so far has never been reported from any Conostigmus (Mikó et al.2016; Dessart 1997; CT personal communictaion). The median portion of the lateral propodeal carina is elevated and forms a bifurcated projection in Conostigmus talamasi that is smaller than that of Megaspilus and most likely represents an intermediate state.

With the discovery of Conostigmus talamasi, the only diagnostic characters for separating Megaspilus from Conostigmus remain the elongate proximal female flagellomeres. The first female flagellomere is more than 2 times as long as the pedicel in Megaspilus, while in other megaspilids, including Conostigmus, it is less than 1.5 times as long as the pedicel. The length of the male and female flagellomeres correlate to each other and are important in species-level diagnosis in Megaspilinae (Mikó et al., 2016). The correlation of flagellomere length between different sexes might be related to their courtship behavior as males extensively antennate and repeatedly touch the female antenna during mating (Liebscher, 1972). Consequently, the first male flagellomere is much longer than the scape in Megaspilus in contrast with other male megaspilids where the first flagellomere is either shorter or slightly longer than the scape (Mikó et al. 2016, Dessart, 1972, 1981, 1974, 1995, 1997, 1999, 2001).

\section{Ceraphronoid and non-ceraphronoid fossils}

To date, there are 18 fossil specimens that share key characteristics with recent Ceraphronoidea (see Supplementary Figure 1), including the compact mesosoma, lyre-shaped notaulus, and the orientation of the antennal bases. Based on their visible morphological characters, these fossils represent (mostly) megaspilid wasps from the Late Cretaceous Santonian to the Early Miocene. There is also a single ceraphronid specimen from the Early Miocene (Supplementary Figure 1).

Wing venation characters are perhaps the most distinctive features shared between these fossils and recent ceraphronoids. In these taxa, a single wing vein is present along the anterior fore wing margin and the stigmal vein is never angled (an angle is present in numerous other taxa in the stigmal vein, marking its intersection with 2RS or r-m veins Mikó et al. (2014)), never tangential to the pterostigma and arising from or anterior to the midpoint of the pterostigma (Fig. 1D, Masner 1993). A single fore wing vein can be found in numerous hymenopteran families, but unlike in these fossils, it is always well separated from the anterior margin.

The remaining fossil hymenopterans currently classified as ceraphronoids (Supplementary Figure 1) lack key ceraphronoid characteristics listed in the introduction. Although they do each possess a pterostigma, the remaining wing venation traits are inconsistent with the superfamily. These taxa might not even be closely related to Ceraphronoidea.

\section{Dendrocerus dubitatus (Brues 1937)}

Dendrocerus dubitatus (Brues 1937) was the first described putative fossil ceraphronoid wasp. Brues (1937) explanation for his placement of this species is the following: "This species is undoubtedly very 
similar to the large modern genus Lygocerus." Most of the body of the holotype specimen is obscured, however, and it is difficult to understand how Brues was able to prepare a rather detailed description as it was outlined by McKellar and Engel (2011).

However, the wing venation on both fore wings are visible (Supplementary Figure 2A.), and they are cardinally different from that of recent ceraphronoids; the straight stigmal vein arises from the anterior portion of and is tangential with the pterostigma (Supplementary Figure 2A.). The antenna of D. dubitatus is composed of only 10 flagellomeres (Supplementary Figure 2B; Brues 1937), a character state that does not occur in any megaspilid taxa. While Ceraphronidae females often have 10 flagellomeres, the vast majority lack the pterostigma (Trassedia females have 11 flagellomeres, Cancemi 1996; Mikó et al.|2013, Masner is only known from male specimens, Mikó and Deans 2009). From these characters, it is clear that this species is not a ceraphronoid wasp. We consider it as incertae sedis and note that it has a wing venation often found in Chrysidoidea, as well as in some Stigmaphronidae.

\section{Stigmaphronidae}

Another prospective ceraphronoid fossil, Allocotidus Muesebeck 1963, was described and classified with the following explanation (Muesebeck, 1963, pg. 129): “... the specimen ... is incomplete and otherwise in rather poor condition. Enough can be clearly made out, however, to place it in the proctotrupoid family Ceraphronidae." (Note that at the time of this description Megaspilidae and Ceraphronidae comprised a single family, Ceraphronidae.) This taxon shares only one characteristic with ceraphronoids, the "fused" SC+R vein, although there is a faint line distinctly separating two wing veins at the anterior margin (a characteristic trait of numerous chrysidoids). Kozlov (1975) placed Allocotidus into his new family Stigmaphronidae, together with three new genera, Stigmaphron Kozlov, Elasmomorpha Kozlov and Hippocoon Kozlov, and provided a diagnosis largely based on traits shared with the Elasminae (flattened hind coxa, elongate tibial spurs, large mesoscutellar axillae complex, shortened metasoma). For reasons that remain unclear Kozlov (1975), and subsequent authors of stigmaphronid taxa (Engel and Grimaldi. 2009: Ortega-Blanco et al. 2011; McKellar and Engel, 2011) considered these shared traits homoplasious, and classified Stigmaphronidae into Ceraphronoidea.

Stigmaphronidae show polymorphisms both in the number of protibial spurs and in wing venation characters. In some species, the two anterior fore wing veins are not adjacent to each other, the stigmal vein is either broken or arched or straight, and it arises anterior or in the middle of the pterostigma. The wing venation, however, never truly exhibits the characteristics of Ceraphronoidea. None of the stigmaphronid species shares any characteristics with recent ceraphronoids, except that some specimens have two protibial spurs. The presence of the two protibial spurs (Figs $3 \mathrm{~A}, \mathrm{~B}$ ) has been long considered a plesiomorphic character state in Ceraphronoidea, despite evidence supporting the evolutionary plasticity of the number of tibial spurs in Apocrita (Basibuyuk and Quicke, 1995; Kaartinen and Quicke, 2007; Engel and Grimaldi. 2009). For example, even within Ceraphronoidea the mesotibial spurs are variable between Megaspilidae and Ceraphronidae.

The protibial spurs are particularly important in Hymenoptera systematics, as the anterior spur has evolved into an antenna cleaning device. This trait is an important synapomorphy for Hymenoptera (Sharkey et al., 2012, Basibuyuk and Quicke, 1995, Vilhelmsen et al., 2010). The posterior spur has been reported as well developed, reduced, or absent in non-apocritans and is usually absent from apocritan taxa. There are known exceptions for two putatively unrelated braconid genera (Rhamnura and Bathyaulax Basibuyuk and Quicke 1995, Kaartinen and Quicke 2007) and recent Ceraphronoidea. This spur is difficult to differentiate from other apical, often unicellular protibial spines and trichoid sensilla (results of the evagination of the membrane of a single epidermal cell) in smaller specimens, even in recent taxa.

It is difficult for us to provide any guidance on how to reclassify stigmaphronids as, given the great polymorphism in tibial spurs, wing venation, and metasomal morphology (Ortega-Blanco et al. 2011), this taxon is likely polyphyletic. Based on the wing venation of Cretaceous chrysidoids, it is possible that stigmaphronids belong in Aculeata. A cenchrus-like area on the metanotum of one species (Engel and Grimaldi 2009) suggests that at least this stigmaphronid might be closely related to some non-apocritan lineages. We consider Stigmaphronidae incertae sedis.

\section{Radiophronidae}

As with Stigmaphronidae, the authors of Radiophronidae failed to provide a robust explanation for why they classified this family into Ceraphronoidea. The only character state this taxon might share with Ceraphronoidea, besides the small body size, is the presence of two protibial spurs (Ortega-Blanco 
et al. 2010). These spurs, however, are difficult to observe in known specimens (Figs 1C1, 4C in OrtegaBlanco et al. 2010). Radiophronidae also lacks the most important ceraphronoid wing characteristics; they have two wing veins along the proximo-anterior margin of the fore wing instead of one, and the shape of the pterostigma is more elongate than in Ceraphronoidea. If the authors interpreted the fossil correctly, the pronotum of Microstaphron is visible in dorsal view and extends posteriorly, while the mesonotum is reduced. Similar modifications can be found in some Ecnomothorax (Megaspilinae), Ecitonetes (Ceraphronidae), and Lagynodes (Lagynodinae) species, but the enlarged pronotum and reduced mesonotum always corresponds to the reduction or absence of wings (Brues, 1902, Dessart and Masner, 1965, Dessart, 1966). Radiophronidae have well-developed wings. On the other hand, the pronotum is usually visible dorsally in Chrysidoidea, e.g. Bethylidae, which have similar wing venation to that of Radiophronidae (Richards, 1939).

Ceraphronoid male genitalia is unique among Apocrita in that they have an independent, moveable apical sclerite, the harpe Mikó et al. (2013). The harpe is absent from the gonostyle-volsella complex of Radiophronidae (Ortega-Blanco et al. 2010). This condition-the absence of a harpe-can only be found in three distantly related recent ceraphronoid species: Trichosteresis glabra, Aetholagynodes stupendus and Dendrocerus wollastoni (Mikó et al., 2013).

Based on the wing venation, mesosomal, and male genitalia morphology, Radiophronidae most likely represents another unique lineage of Cretaceous chrysidoid wasps and should be considered incertae sedis.

\section{Is Ceraphronoidea the most structurally diverse hymenopteran superfamily?}

Superfamilies, among the highest taxonomic ranks (family-level) that are regulated by the ICZN (1999), serve as important taxa for communicating about Hymenoptera evolution (see Sharkey et al. 2012). They represent the highest functional and pragmatic taxa, defined, in part, by their natural history and a set of distinct morphological characteristics. It is critical, therefore, that they remain monophyletic and free from extraneous, unrelated taxa.

Recent and fossil Ceraphronidae and Megaspilidae, including Conostigmus talamasi, comprise a monophyletic group that can be clearly defined using numerous apomorphic traits (Masner, 1993). The inclusion of Stigmaphronidae, Radiophronidae and, until recently, the stephanoid Aptenoperissidae and the trigonaloid Maimetshidae (Zhang et al., 2018; Perrichot et al., 2011) within Ceraphronoidea, however, results in a polyphyletic morass that cannot be confidently diagnosed. The resulting taxon would have a variable number of protibial spurs and flagellomeres, the presence and absence of a wasp waist, tarsal plantulae, and cenchri, and either a compact or unabridged mesosoma-i.e., traits that are characteristic of other, well defined superfamilies. Ceraphronoidea has clearly been treated as a waste bin for minute fossil taxa with a pterostigma. Based on the characteristics of those fossils we remove these taxa from Ceraphronoidea.

\section{ACKNOWLEDGMENTS}

We give thanks to Elijah Talamas (Florida State Collection of Arthropods), who drew our attention to this unique fossil, and to Christel and Hans Werner Hoffeins, who loaned us the specimens. Analytical tools used in this study were provided by the projects ASTOR and NOVA (Michael Heethoff, TU Darmstadt; Vincent Heuveline, Heidelberg University; Jürgen Becker, Karlsruhe Institute of Technology). We especially thank the following co-workers: Felix Beckmann, Jörg Hammel, Andreas Kopmann, Philipp Lösel, Wolfgang Mexner, Tomy dos Santos Rolo, Nicholas Tan Jerome, Matthias Vogelgesang, Tomáš Faragó, Sebastian Schmelzle.

\section{SUPPLEMENTARY INFORMATION}

Supplementary Figure 1. Timeline of fossils that have been classified as Ceraphronoidea. Names above the timeline are now considered as Ceraphronoidea, while names below are taxa removed from Ceraphronoidea and considered as incertae sedis $(\mathrm{R}=\mathrm{Radiophronidae}, \mathrm{S}=\mathrm{Stigmaphronidae}, \mathrm{M}=$ Megapilidae, $\mathrm{Ce}=$ Ceraphronidae; references cited on the Figure: Rasnitsyn (1991); Engel and Grimaldi (2009); OrtegaBlanco et al. (2011, 2010); Muesebeck (1963); Kozlov (1975); McKellar and Engel (2011); Brues (1937); Alekseev and Rasnitsyn (1981); Alekseev (1995); Brues (1940); Szabó and Oehlke (1986); Dessart (1977); Engel (2013); Peñalver and Engel (2006) Supplementary Figure 2. Brightfield images of the holotype 
of Dendrocerus dubitatus Brues 1937. This species is considered now as incertae sedis. Supplementary 3D PDF. 3D PDF of Conostigmus talamasi sp. nov. holotype (DEI-GISHym31819). Supplementary Table 1. Measurements of anatomical lines.

\section{REFERENCES}

Alekseev, V. N. (1978). Basoko Risbec (Hymenoptera, Ceraphronoidea), a genus new to the Palearctic fauna, and an identification key to the genera of the Ceraphronoidea. Entomologicheskoye Obozreniye, 57:654-660.

Alekseev, V. N. (1995). Conostigmus antiquus sp. n., a fossil ceraphronoid species from Baltic amber (Hymenoptera, Ceraphronoidea). Amber \& Fossils, 1:23-25.

Alekseev, V. N. and Rasnitsyn, A. P. (1981). [Late Cretaceous Megaspilidae (Hymenoptera) from amber of the Taymyr.]. Paleontologicheskii zhurnal, 4:127-130.

Balhoff, J. P., Mikó, I., Yoder, M. J., Mullins, P. L., and Deans, A. R. (2013). A semantic model for species description applied to the ensign wasps (Hymenoptera: Evaniidae) of New Caledonia. Systematic Biology, 62(5):639-659.

Basibuyuk, H. H. and Quicke, D. L. (1995). Morphology of the antenna cleaner in the Hymenoptera with particular reference to non-aculeate families (insecta). Zoologica Scripta, 24(2):157-177.

Branstetter, M. G., Danforth, B. N., Pitts, J. P., Faircloth, B. C., Ward, P. S., Buffington, M. L., Gates, M. W., Kula, R. R., and Brady, S. G. (2017). Phylogenomic insights into the evolution of stinging wasps and the origins of ants and bees. Current Biology, 27(7):1019-1025.

Brues, C. T. (1902). New and little-known guests of the Texas legionary ants. American Naturalist, 36:365-378.

Brues, C. T. (1937). Superfamilies Ichneumonoidea, Serphoidea, and Chalcidoidea. In Carpenter, F. M., editor, Insects and arachnids from Canadian amber, pages 7-62. University of Toronto studies. Geological series volume 40.

Brues, C. T. (1940). Calliceratidae in Baltic amber. Proceedings of the American Academy of Arts \& Sciences, 73:265-269.

Cancemi, P. (1996). Trassedia luapi n. gen., n. sp. from Madagascar (Hymenoptera, Ceraphronoidea, Megaspilidae). Giornale Italiano di Entomologia, 8:231-233.

Dessart, P. (1966). Contribution a l'etude des Hymenopteres Proctotrupoidea. (X) Revision des genres Lagynodes Foerster, 1840, et Plastomicrops Kieffer, 1906 (Ceraphronidae). Bulletin de l'Institut Royal des Sciences Naturelles de Belgique. Entomologie, 42:1-85.

Dessart, P. (1972). Contribution a la revision du genre Megaspilus Westwood, 1829 (Hymenoptera, Ceraphronoidea, Megaspilidae). Bulletin-Institut royal des sciences naturelles de Belgique, 48(7):1-55.

Dessart, P. (1974). Les mégaspilides européens [Hym. Ceraphronoidea] parasites des diptéres syrphides avec une révision du genre Trichosteresis. Annales de la Société Entomologique de France (n.s.), 10:395-448.

Dessart, P. (1977). Contribution a l'etude des Lagynodinae (Hym. Ceraphronoidea Megaspilidae). Bulletin et annales de la Société royale belge d'entomologie, 113:277-319.

Dessart, P. (1981). Le genre Megaspilus Westwood, 1829, en Amerique du Nord (Hymenoptera, Ceraphronoidea, Megaspilidae). Bulletin de l'Institut royal des sciences naturelles de Belgique. Entomologie, 53(11):1-11.

Dessart, P. (1995). À propos du genre DendrocerusRatzeburg, 1852. Les espèces du group "penmaricus" (Hymenoptera Ceraphronoidea Megaspilidae). Bulletin et annales de la Société royale belge d'entomologie, 131.

Dessart, P. (1997). Les Megaspilinae ni européens, ni américains. 1. Le genre Conostigmus Dahlbom, 1858 (Hym. Ceraphronoidea Megaspilidae). Memoires de la Société Royale Belge d'Entomologie, 37:3-144.

Dessart, P. (1999). Révision des Dendrocerus du groupe «halidayi (Hym. Ceraphronoidea Megaspilidae). Belgian Journal of Entomology, 1:169-275.

Dessart, P. (2001). Les Megaspilinae ni européens, ni américains 2. Les Dendrocerus Ratzeburg, 1852, à mâles non flabellicornés (Hymenoptera Ceraphronoidea Megaspilidae). Belgian Journal of Entomology, 3:3-124.

Dessart, P. and Masner, L. (1965). Contribution a l'etude des Hymenopteres Proctotrupoidea (VII). 
Ecnomothorax, genre nouveau de Ceraphronidae Megaspilinae. Bulletin et annales de la Société royale belge d'entomologie, 101:275-288.

dos Santos Rolo, T., Ershov, A., van de Kamp, T., and Baumbach, T. (2014). In vivo X-ray cinetomography for tracking morphological dynamics. Proceedings of the National Academy of Sciences of the USA, 111(11):3921-3926.

Dowton, M., Austin, A., Dillon, N., and Bartowsky, E. (1997). Molecular phylogeny of the apocritan wasps: the Proctotrupomorpha and Evaniomorpha. Systematic Entomology, 22(3):245-255.

Engel, M. S. (2013). A ceraphronid wasp in Early Miocene amber from the Dominican Republic (Hymenoptera: Ceraphronidae). Novitates Paleoentomologicae, 2:1-6.

Engel, M. S. and Grimaldi, D. A. (2009). Diversity and phylogeny of the mesozoic wasp family Stigmaphronidae (Hymenoptera: Ceraphronoidea). Denisia, 26:53-68.

Ernst, A., Mikó, I., and Deans, A. (2013). Morphology and function of the ovipositor mechanism in Ceraphronoidea (Hymenoptera, Apocrita). Journal of Hymenoptera Research, 33:25.

Gillung, J. P. and Winterton, S. L. (2018). A review of fossil spider flies (Diptera: Acroceridae) with descriptions of new genera and species from Baltic amber. Journal of Systematic Palaeontology, 16(4):325-350.

Heraty, J., Ronquist, F., Carpenter, J. M., Hawks, D., Schulmeister, S., Dowling, A. P., Murray, D., Munro, J., Wheeler, W. C., Schiff, N., and Sharkey, M. (2011). Evolution of the hymenopteran megaradiation. Molecular Phylogenetics and Evolution, 60(1):73-88.

Hoffeins, H. (2001). On the preparation and conservation of amber inclusions in artificial resin. Polskie Pismo Entomologiczne, 70(3).

ICZN (1999). International Code of Zoological Nomenclature. Fourth Edition. The International Trust for Zoological Nomenclature, London. Available (with amendments) online: http://www. iczn org/iczn/index.jsp

Kaartinen, R. and Quicke, D. L. (2007). A revision of the parasitic wasp genus Bathyaulax Szépligeti (Hymenoptera: Braconidae: Braconinae) from Africa and the Arabian Peninsula. Journal of Natural History, 41(1-4):125-212.

Keller, R. A., Peeters, C., and Beldade, P. (2014). Evolution of thorax architecture in ant castes highlights trade-off between flight and ground behaviors. Elife, 3:e01539.

Klopfstein, S., Vilhelmsen, L., Heraty, J. M., Sharkey, M., and Ronquist, F. (2013). The hymenopteran tree of life: evidence from protein-coding genes and objectively aligned ribosomal data. PLoS ONE, 8(8):e69344.

Kozlov, M. (1975). Family Stigmaphronidae Kozlov, fam. nov. In Rasnitsyn, A., editor, Hymenoptera Apocrita of the Mesozoic (Trudy Paleontologicheskogo Instituta, Akademii Nauk SSSR 174 [Transactions of the Paleontological Institute, Academy of Sciences USSR]), pages 75-81.

Larsson, S. G. (1978). Baltic amber: a palaeobiological study. Scandinavian Science Press.

Liebscher, S. (1972). Zur Taxonomie und Biologie von Dendrocerus-Arten (Hymenoptera, Ceraphronoidea: Megaspilidae) im Hyperparasitenkreis der Lachnidae (Homoptera, Aphidoidea) auf Pinus und Larix. $\mathrm{PhD}$ thesis, Technical University of Dresden, Dresden.

Lösel, P. and Heuveline, V. (2016). Enhancing a diffusion algorithm for 4D image segmentation using local information. Proceedings of SPIE, 9784:9784L.

Mao, M., Gibson, T., and Dowton, M. (2015). Higher-level phylogeny of the Hymenoptera inferred from mitochondrial genomes. Molecular Phylogenetics and Evolution, 84:34-43.

Masner, L. (1993). Superfamily Ceraphronoidea. Hymenoptera of the World: An identification guide to families, pages 566-569.

McKellar, R. C. and Engel, M. S. (2011). New Stigmaphronidae and Megaspilidae (Hymenoptera: Ceraphronoidea) from Canadian Cretaceous amber. Cretaceous Research, 32(6):794-805.

Mexner, W., Bonn, M., Kopmann, A., Mauch, V., Ressmann, D., Chilingaryan, S. A., Jerome, N. T., van de Kamp, T., Heuveline, V., Lösel, P., Schmelzle, S., and Heethoff, M. (2017). OpenGL® API-based analysis of large datasets in a cloud environment. Design and Use of Virtualization Technology in Cloud Computing, page 161.

Mikó, I., Copeland, R. S., Balhoff, J. P., Yoder, M. J., and Deans, A. R. (2014). Folding wings like a cockroach: a review of transverse wing folding ensign wasps (Hymenoptera: Evaniidae: Afrevania and Trissevania). PLoS One, 9(5):e94056.

Mikó, I. and Deans, A. (2009). Masner, a new genus of Ceraphronidae (Hymenoptera, Ceraphronoidea) 
described using controlled vocabularies. Advances in the Systematics of Hymenoptera: Festschrift in honour of Lubomír Masner. ZooKeys, 20:127-153.

Mikó, I., Masner, L., Johannes, E., Yoder, M. J., and Deans, A. R. (2013). Male terminalia of Ceraphronoidea: morphological diversity in an otherwise monotonous taxon. Insect Systematics \& Evolution, 44(3-4):261-347.

Mikó, I., Trietsch, C., Sandall, E. L., Yoder, M. J., Hines, H., and Deans, A. R. (2016). Malagasy Conostigmus (Hymenoptera: Ceraphronoidea) and the secret of scutes. PeerJ, 4:e2682.

Muesebeck, C. F. W. (1963). A new ceraphronid from Cretaceous amber (Hymenoptera: Proctotrupoidea). Journal of Paleontology, 37:129-130.

Olmi, M. (1994). The Dryinidae and Embolemidae (Hymenoptera: Chrysidoidea) of Fennoscandia and Denmark. Number 30 in Fauna Entomologica Skandinavica.

Ortega-Blanco, J., Delclòs, X., and Engel, M. S. (2011). Diverse stigmaphronid wasps in early Cretaceous amber from Spain (Hymenoptera: Ceraphronoidea: Stigmaphronidae). Cretaceous Research, 32(6):762773.

Ortega-Blanco, J., Rasnitsyn, A. P., and Delclòs, X. (2010). A New Family of ceraphronoid Wasps from Early Cretaceous Álava Amber, Spain. Acta Palaeontologica Polonica, 55(2):265-276.

Penney, D. (2010). Biodiversity of fossils in amber from the major world deposits. Siri Scientific Press.

Perrichot, V., Ortega-Blanco, J., McKellar, R. C., Delclos, X., Azar, D., Nel, A., Tafforeau, P., and Engel, M. S. (2011). New and revised maimetshid wasps from cretaceous ambers (hymenoptera, maimetshidae). ZooKeys, (130):421.

Peters, R. S., Krogmann, L., Mayer, C., Donath, A., Gunkel, S., Meusemann, K., Kozlov, A., Podsiadlowski, L., Petersen, M., Lanfear, R., Diez, P., Heraty, J., Kjer, K., Klopfstein, S., Meier, R., Polidori, C., Schmitt, T., Liu, S., Zhou, X., Wappler, T., Rust, J., Misof, B., and Niehuis, O. (2017). Evolutionary history of the Hymenoptera. Current Biology, 27(7):1013-1018.

Peters, R. S., Meyer, B., Krogmann, L., Borner, J., Meusemann, K., Schütte, K., Niehuis, O., and Misof, B. (2011). The taming of an impossible child: a standardized all-in approach to the phylogeny of Hymenoptera using public database sequences. BMC Biology, 9(1):55.

Peñalver, E. and Engel, M. S. (2006). Two wasp families rare in the fossil record (Hymenoptera): Perilampidae and Megaspilidae from the Miocene of Spain. American Museum Novitates, 3540:1-12.

Rasnitsyn, A. (1991). Early cretaceous members of evaniomorphous hymenopterans of the families Stigmaphronidae and Cretevaniidae and subfamily kotujellitinae (gasteruptiidae). Paleontologicheskii zhurnal, 4:128-132.

Reid, J. (1941). The thorax of the wingless and short-winged Hymenoptera. Ecological Entomology, 91(8):367-446.

Richards, O. W. (1939). The British Bethylidae (s.l.) (Hymenoptera). Ecological Entomology, 89(8):185344.

Ronquist, F., Rasnitsyn, A. P., Roy, A., Eriksson, K., and Lindgren, M. (1999). Phylogeny of the Hymenoptera: a cladistic reanalysis of Rasnitsyn's (1988) data. Zoologica Scripta, 28(1-2):13-50.

Ruthensteiner, B. and Heß, M. (2008). Embedding 3D models of biological specimens in PDF publications. Microscopy Research and Technique, 71(11):778-786.

Sadowski, E.-M., Seyfullah, L. J., Wilson, C. A., Calvin, C. L., and Schmidt, A. R. (2017). Diverse early dwarf mistletoes (Arceuthobium), ecological keystones of the Eocene Baltic amber biota. American Journal of Botany, 104(5):694-718.

Sharkey, M. J., Carpenter, J. M., Vilhelmsen, L., Heraty, J., Liljeblad, J., Dowling, A. P., Schulmeister, S., Murray, D., Deans, A. R., Ronquist, F., Krogmann, L., and Wheeler, W. (2012). Phylogenetic relationships among superfamilies of Hymenoptera. Cladistics, 28(1):80-112.

Szabó, J. B. and Oehlke, J. (1986). Neu Proctotrupoidea aus dem Baltischen Bernstein. Beiträge zur Entomologie, 36:99-106.

van de Kamp, T., dos Santos Rolo, T., Vagovič, P., Baumbach, T., and Riedel, A. (2014). Threedimensional reconstructions come to life-interactive 3D PDF animations in functional morphology. PLoS One, 9(7):e102355.

Vilhelmsen, L., Mikó, I., and Krogmann, L. (2010). Beyond the wasp-waist: structural diversity and phylogenetic significance of the mesosoma in apocritan wasps (insecta: Hymenoptera). Zoological Journal of the Linnean Society, 159(1):22-194.

Vogelgesang, M., Chilingaryan, S., dos_Santos Rolo, T., and Kopmann, A. (2012). UFO: A scalable 
GPU-based image processing framework for on-line monitoring. In High Performance Computing and Communication \& 2012 IEEE 9th International Conference on Embedded Software and Systems (HPCC-ICESS), 2012 IEEE 14th International Conference on Communication Technology (ICCT), pages 824-829. IEEE.

Wolfe, A. P., McKellar, R. C., Tappert, R., Sodhi, R. N., and Muehlenbachs, K. (2016). Bitterfeld amber is not Baltic amber: Three geochemical tests and further constraints on the botanical affinities of succinite. Review of Palaeobotany and Palynology, 225:21-32.

Zhang, Q., Rasnitsyn, A. P., Wang, B., and Zhang, H. (2018). New data about the enigmatic wasp from mid-Cretaceous Burmese amber (Hymenoptera, Stephanoidea, Aptenoperissidae). Cretaceous Research, 84:173-180. 